\title{
FUNCION DEL CUENTO LATINOAMERICANO
}

\author{
POR \\ LEO POLLMANN \\ Universität Regensburg (Ratisbona)
}

El cuento tiene un función central en el conjunto de la literatura latinoamericana y su desarrollo como autodescubrimiento gradual de un continente. Dicha función está en relación con la estructura del cuento en general, pero también con las características particulares que éste ha adquirido en Latinoamérica. Puede decirse que el cuento latinoamericano es un ejemplo especialmente claro del cuento: los atributos propios del género aparecen en él con extrema claridad y agudeza. Esto nos permitirá plantear algunas preguntas íntimamente conexas nada fáciles de responder: qué es un cuento en general y qué caracteriza al cuento latinoamericano en particular, y la pregunta por la función de éste dentro de la literatura latinoamericana. Esta última pregunta nos conducirá a echar una ojeada a algunas importantes etapas históricas del cuento.

La etimología de la palabra «cuento» nos da un punto de partida para determinar el género: el cuento es una narración en la cual el acto mismo de narrar, y más precisamente, el acto de narrar con pericia y arte, tiene una importancia constitutiva. Una visión de cualquier corpus de cuentos nos enseña que este arte de narrar se demuestra de modo ejemplar dentro de una unidad abarcable. Aquí aparece lo que podría llamarse el carácter de muestra propio del cuento. Bajo distintos aspectos, el cuento tiene un carácter experimental: el autor da al lector una prueba de su habilidad; primero pone a prueba sus propias posibilidades y luego entrega una muestra de la realidad y de una determinada clase de realidad que le dice algo y le hace pensar. Esta realidad puede ser, por ejemplo, regional, campestre o una en que aparecen las contradicciones entre el campo y la ciudad; puede ser una realidad fantástica, u onírica, fabulosa o también temática; por ejemplo, de amor o de «amor, locura y muerte». La tendencia a relacionar el concepto «cuento» (o 
«conte») con un epíteto específico fortalece este rasgo característico: «cuento vasco», «cuento peruano», «conte moral», «conte merveilleux», «conte de fée», «conte oriental», «conte phantastique», etc.; todas ellas son posibilidades de unificar los «cuentos» o «contes» según clases de muestras. Con su carácter de prueba se halla también en relación el hecho de que el cuento aparece preferentemente agrupado en un corpus. Aquí se fundamentará aquello que podríamos denominar la dimensión meditativo-filosófica del cuento: a mentıdo, en tiempos de ruptura y de crisis de la autocomprensión, el cuento toma la función de una especie de reflexión sobre el objeto. Voltaire, Diderot y Unamuno no se han avergonzado del cuento o del «conte», sino que lo han practicado y han influido de modo decisivo en este género literario. Balzac escribe «contes» para ponerse en claro con sus tendencias iluministas (Le chef d'oeuvre inconnu, Gambara); Nodier y Gautier introducen el «conte» para sondear el ámbito de lo fantástico; Zola escribe «contes» para objetivar y liberarse de su relación todavía romántica con la Provence; Maupassant hace del «conte» un género directivo en el momento en que la novela naturalista se ha vuelto cuestionable y han surgido a la vista nuevos ámbitos internos de la realidad que no se dejaban alcanzar con la actitud y procedimiento del Naturalismo. Unamuno también escribe cuentos para rastrear al hombre interior, en un intento por sacar a luz, artísticamente, una realidad que permanecía oculta para el narrador naturalista. El cuento posee esta capacidad de cambio y de apropiación del espacio interior porque él, como se dijo, toma sólo muestras, y por ello no necesita respetar contextos mayores.

El cuento es ampliamente libre en el manejo de las leyes de la mímesis que copia: él puede copiar, pero no necesita hacerlo. Aquí se verá claro por qué el cuento, justamente en América Latina, ha logrado tanta significación. El cuento puede moverse en función experimental en nuevos ámbitos de la realidad, familiares a lo latinoamericano, en lo mágico, en lo maravilloso, en lo fantástico. Y puede dejar de lado las formas constructivas, cargadas de tradición occidental; siendo en primer lugar lenguaje artístico, el cuento puede reflexionar, en inmediata relación con el objeto, sobre la realidad latinoamericana. Así, el cuento es un medio experimental que permite a los autores latinoamericanos realizar para su continente el tan difícil camino del autodescubrimiento y hallazgo. Por ello se puede encontrar el cuento en América Latina en una forma particularmente pura y neta: aquí está en su elemento, y puede decirse que se halla en un doloroso acuerdo ideal con las condiciones de la producción literaria, con una situación análoga a la de Sísifo, que excluye toda llegada definitiva. Con ello no pienso en novelas cortas, tales como 
las que, siguiendo a Chateaubriand y Bernardin de Saint-Pierre ${ }^{1}$, se escribieron en América Latina a comienzos del siglo XIX, aunque también hay que señalar que el seguir modelos europeos fue y es un paso importante en el camino del autohallazgo. E1 cuento al que me refiero es el que comienza a cristalizarse en la segunda mitad del siglo XIX, por ejemplo, en las Tradiciones peruanas (1872-1883) de Ricardo Palma. Ellas son muestras de la realidad peruana, que su autor ha compuesto «con mucho cuidado y limpieza» ${ }^{2}$. Son un conjunto de relatos que no pretenden poseer una estructura dramática cerrada, con comienzo, peripecia y fin, sino que permanecen abiertos y que por medio de americanismos y neologismos fortalecen su voluntad de constituir las «tradiciones peruanas», en su peculiaridad, como objeto de la observación. A veces quedan abiertos casi tanto como un essai de Montaigne ${ }^{3}$. No es ninguna casualidad que el cuento latinoamericano, en sentido moderno, comience a formarse hacia $1880^{4}$. Se da entonces el comienzo de un giro hacia dentro, que

\footnotetext{
${ }^{1}$ Así Pablo de Olavide ya a fines del siglo. Véase Pablo de Olavide, Obras narrativas escogidas (Lima, 1971, introducción de E. Núñez).

${ }^{2}$ Prólogo de Tradiciones peruanas. Sobre este tema véase José Miguel Oviedo en Ricardo Palma, Cien tradiciones peruanas (Venezuela, Biblioteca Ayacucho, 1977), pp. IX-XLV.

${ }^{3}$ Un ejemplo especialmente notable es «Bolívar y el cronista Calancha», de 1883. El cuento es divisible en tres partes, de las cuales sólo la tercera tiene una estructura predominantemente narrativa. La primera parte comienza con una comprobación general (todavía hay realistas en el Perú); luego, mediante tres ejemplos y un detalle costumbrista (los patriotas usan «capas de colores oscuros»; los realistas, «capa de paño grana»), se relaciona esa comprobación con una larga tradición peruana. La segunda parte empieza con cuatro oraciones que introducen el cuento propiamente dicho, la narración de Bolívar (Bolívar es recibido en Cuzco). Luego siguen cinco testimonios en favor de Bolívar y el rechazo de un sexto por considerárselo parcial. La tercera parte (que abarca sólo un buen tercio del total) refiere la visita de inspección de Bolívar, su asombro ante alguien a quien todos alaban, su desconfianza y su súbita comprensión del caso en medio de la noche. El relato desemboca, tal como mutchos essais de Montaigne, en una sentencia moral: "No es más infeliz el que no tiene amigos, sino el que no tiene enemigos, porque eso prueba que no tiene honra que le murmuren, valor que le teman, riqueza que le codicien, bienes que le esperen ni nada btieno que le envidien» (Cien tradiciones peruanas, loc. cit., p. 266). Luego de esta máxima, que honraría a cualquier moralista, Bolívar despide al intachable sujeto.

“Ya la temprana «tradición» «Don Dimas de la Tijereta» (1864) tiene carácter «episódico». En ella muestra Palma su gusto por la digresión y por la ocurrencia repentina, así como su conciencia de sí mismo como narrador, disimulada en el comentario modesto: "Yo, pobre y mal traído narrador de cuentos». Con todo se puede comprobar muy fácilmente un predominio progresivo de la estructura digresivo-ensayística en los cuentos de Palma, desde «Don Dimas», pasando por «iPues bonita soy yo, la Castellanos!» y por "La emplazada» hasta "Bolívar y el cronista Calancha».
} 
anuncia el de nuestro siglo, el comienzo de una actualidad que pone de manifiesto lo específico del cuento: su aptitud para la investigación linguiística del espacio interior. El cuento «o espelho» (1882) de Machado de Asís es un retoño característico y logrado de esta hora de nacimiento del «cuento» o «conto». Lo típico comienza ya con el cuadro en el que acontece el cuento. Este lleva el título de «Papeis avulsos»: se subraya con ello el carácter de muestra de «O espelho». Machado de Asís relata en este cuento, que en sí considerado es una pequeña narración de marco, cómo algunos señores se reúnen por la noche y discuten acerca de problemas metafísicos. Uno de ellos expone la tesis según la cual existen un «alma exterior» y un «alma interior» y relata luego un «casus» que aclara ello. Es el de un alférez, quien, un día en que su tía se halla de viaje y a él se le han escapado los esclavos, se siente tan dominado por el «alma interior» que a toda prisa se pone el uniforme de gala y se mira al espejo, para que el «alma exterior» mantenga el dominio y él pueda volver a ser dueño de la situación ${ }^{5}$. El cuento tiene aquí, como muestra del arte narrativo, la función de reflexionar la relación del hombre con la realidad y consigo mismo. Su autor aborda una temática que poco después retomará José Enrique Rodó en su Ariel (1900): la de la exterioridad que en aquella época amenazaba ahogar a la verdadera América Latina, y de una interioridad que tanto Rodó como Machado de Asís aspiraban para su patria. Vemos cuán cerca se hallan el cuento y el ensayo.

Pero cuando hablamos del cuento latinoamericano pensamos ciertamente más en autores contemporáneos, como Horacio Quiroga, Jorge Luis Borges, João Guimarães Rosa, Augusto Roa Bastos, Julio Cortázar y otros. En las obras de estos autores se ve ejemplarmente reforzada la función que puede ejercer y que ha ejercido el cuento latinoamericano dentro del conjunto del sistema de los géneros literarios, en el desarrollo de un autor y en el marco de la historia latinoamericana. El cuento de Horacio Quiroga equivale, en este sentido, a la apertura de un campo de experimentación sobre aquellas cuestiones del amor, de la locura y de la muerte, que eran la preocupación de su tiempo; preocupación despertada tras el encuentro con narradores europeos, especialmente con Dostoyevski y con Maupassant, que habían planteado estos problemas de modo ejemplar. Visto formalmente, su cuento no es un paso tan decisivo en la dirección del cuento contemporáneo como el de Ricardo Palma, sino más

${ }^{5}$ Sobre esto véase L. Pollmann en Studia Iberica, número especial dedicado a Hans Flasche, editado por K.-H. Körner y K. Rühl (Berna y Munich, 1972), pp. $467-478$. 
bien un retorno a modelos europeos, conscientemente transformados según el modo de la «barbarie» y a veces de lo fantástico ${ }^{6}$.

Con Historia universal de la infamia (1934) nos acercamos al cuento puro, al cuento moderno, latinoamericano hasta lo más íntimo de sus estructuras narrativas. Las «historias» de la Historia universal son, como el autor mismo dice, en primer lugar, ejercicios de estilo, pero luego también, y nuevamente en palabras del autor, «ejemplos de magia»? Esta última es una declaración tematológica, pero los «ejemplos de magia» que Borges aquí, como él mismo dice, «narra», implican también un ligero cambio en el discurso. La importancia de Historia universal reside sobre todo en que aquí el cuento, como campo experimental del acto de relatar y como muestra metafísica, como muestra en la que el arte narrativo y su nueva dimensión, la apertura del «espacio interior», se goza y paladea como el vino en la boca. Cuando Borges explica que él narra simplemente estas historias y lo prueba mediante citas de fuentes, quiere señalar con ello que su objeto primario no es la realidad externa, sino la interna, la de la literatura. El libro se halla aquí en una línea que comienza con la «mise en abîme» de Gide, quien también se incluye entre quienes toman como objeto el horizonte de la literatura. Sería inadecuado concluir de ello que los cuentos de Borges no son latinoamericanos, ni argentinos ni originales. En Buenos Aires se vive en y con libros al menos tanto como en y con la realidad externa palpable, para no hablar del tiempo en que se ocupa uno en mezclar en el sueño lo poco de realidad externa recibida con los propios sueños. Esta ciudad, con sus intelectuales ávidos de lectura, es el escenario de los cuentos borgianos.

Las muestras del arte narrativo que nos da Borges en Historia universal prueban también la provisoriedad señalada al comienzo y su inconclusibilidad y apertura del cuento en cuanto búsqueda; lo cual puede decirse, con mayor razón aún, de los cuentos maduros de la colección El aleph (1949). Estos, con su lenguaje sobrio y embriagador al mismo tiempo, abren al lector la dimensión de lo indecible, de lo fantástico, de lo misterioso, del mundo interno y una verdadera fiesta del silencio ${ }^{8}$.

\footnotetext{
- Se pueden distinguir por lo menos dos tipos: un cuento como «Una estación de amor", que en realidad es una novela breve (una "novela corta»), y cuentos como «La gallina degollada» $\mathrm{y}$ «El solitario», que terminan en un desenlace «bárbaro».

${ }^{7}$ Sobre esto véase mi trabajo «El espantoso redentor. La poética inmanente de 'Historia universal de la infamia'», en Revista Iberoamericana, 108-109 (1979), pp. 459-473).

${ }^{8}$ Véase sobre esto Gabriela Massuh, Borges. Una estética del silencio (Buenos Aires: Ed. Sudamericana, 1980).
} 
Son la vivencia fascinante de lo eternamente provisorio, de los espejos que reflejan en otros espejos, de una búsqueda que se estiliza en el laberinto del lenguaje en un éxtasis de ritualidad literaria. La nueva novela latinoamericana, especialmente el realismo mítico ", es impensable sin este cuento puro. Borges no ha escrito novelas, al menos no ha publicado ninguna, pero la nueva novela latinoamericana, paradojalmente, es creación suya. La coincidencia temporal de la hora inicial de la nueva novela latinoamericana y la madurez del cuento borgeano, de Hombres de maíz, El reino de este mundo y El aleph, no es mera casualidad, es un indicio en favor de que Borges, con sus cuentos e «historias», ha contribuido de modo decisivo a convertir en literario aquello «maravilloso» de que habla Carpentier en el prólogo a El reino de este mundo. El caso Borges es representativo de una relación fundamental existente entre el cuento y la novela. El cuento hace de avanzada de la novela, es un probar un nuevo terreno y un nuevo lenguaje. Gracias a la estructura del cuento puede esta prueba, como lo ilustra el caso de Borges, convertirse en una obra maestra literaria y ser consciente de su autonomía.

Esta consciencia pertenece a las características del cuento, que puede exhibirla como un orgullo del género. El cuento no se abre; es, por así decir, un «género macho» que los latinoamericanos llevan en la propia piel ${ }^{10}$. Este género no ha de ser confundido con la novela corta o la novela ejemplar. Novela corta y novela ejemplar, como ya sus nombres lo indican, pueden abrirse fácilmente a la novela porque su tendencia a la aventura y a la construcción dramática, la falta del carácter de muestra, su relativa «completes» y su pretensión de totalidad ejemplar y fuertes rasgos miméticos hacen de ellas pequeñas novelas. Yo sé que la posibilidad de una distinción entre «cuento» y «novela corta» es discutida y que los autores franceses utilizan los conceptos "conte» y «nouvelle» como intercambiables, pero la realidad del cuento latinoamericano reclama precisamente una distinción tipológica ideal, y la hace necesaria.

Es que en América Latina predomina sin duda el tipo cuento, mientras que en España predominaron durante siglos la novela ejemplar y la novela corta, que incluso dieron a la novela el nombre genérico. En Alemania y Francia el porcentaje de cuentos y novelas cortas está más o menos equilibrado, por lo cual es muy difícil distinguir en estos países entre ambos géneros; aquí, incluso puede, en algunos casos, sonar a pedante el pretender hacerlo. En América Latina, por el contrario, existen pocos

'He propuesto este concepto en lugar del de «realismo mágico» en mi Geschichte des lateinamerikanischen Romans, 1815-1978 (Berlín, 1980).

${ }^{10} \mathrm{Me}$ refiero a pensamientos de Octavio Paz en El laberinto de la soledad. 
ejemplos de novelas cortas: Una estación de amor es uno de estos ejemplos, y éste, significativamente, debe mucho a la tradición europea. Quien no sabe apreciar el carácter propio del cuento con respecto a la novela corta o novela ejemplar, corre el peligro de descuidar la idiosincrasia del cuento latinoamericano y su función en relación con la novela. El cuento, al contrario de la novela ejemplar o novela corta, no tiende a perderse en la novela; la fructifica, más bien, guardando su autonomía y otredad. Esta otredad radica en lo que podría llamarse su ambiguiedad profunda. Por un lado, es un género breve, linguísticamente cerrado y denso, como tiene que serlo una muestra ilustrativa. Por otro, es un género infinitamente abierto ${ }^{11}$, atento. Es el género de la atención meditativa. Mientras que en la novela, y también hasta cierto punto en la novela corta, la realidad exterior adquiere cierta independencia con respecto al autor (como lo dijo muy bien y oportunamente Cortázar), en el cuento la mirada del narrador, instrumento de la atención del autor y medio de su arte linguístico, domina la materia. Gracias a esta autonomía y otredad, el cuento adquiere su función frente a la novela. En relación con este fenómeno es especialmente interesante observar los casos de autores que comenzaron escribiendo cuentos y acabaron por escribir novelas. Me refiero a tres casos paradigmáticos: el de João Guimàrães Rosa, el de Augusto Roa Bastos y el de Juan Rulfo (el caso Julio Cortázar sería, naturalmente, muy interesante también, pero se trata de una materia demasiado extensa para ser tratada aquí). En los «contos de Sagarana, proveniente del modernismo brasileño y del naturalismo regionalista, Guimarães Rosa ensaya un nuevo estilo y una nueva sensibilidad y crea muestras inolvidables de realidad latinoamericana, tales como la de los bueyes que marchando bajo el yugo intercambian experiencias. En Grande Sertão: Veredas, por el contrario, amplía la perspectiva con la pregunta por la legitimidad o ilegitimidad de la existencia en el Sertão: la estructura de muestra es aquí reprimida por la pregunta por el todo. «Cuento»y «novela» son aquí dos fases y escalones que conservan cada

${ }^{11}$ Esta apertura está en relación con su carácter discontinuo. Mientras que novela corta y novela ejemplar, como la novela tradicional, tienen estructura continua con comienzo, peripecia y fin, el cuento tiende a cortar su acción, a introducir digresiones y nuevos hilos narrativos, a finalizar bruscamente, a ser muy breve, casi fragmentario. Me permito señalar a este respecto que en árabe la palabra para narrar, qașsa, significa al mismo tiempo cortar (véase Hans Weber, Arabisches Wörterbuch, 3. a ed., Leipzig, 1958, p. 682), una coincidencia de significados que ya existía en tiempos antiguos (información del orientalista W. D. Fischer Erlangen). Es que los primitivos narradores no buscaban ni la estructura refinada literaria, ni siquiera la unidad de una historia bien delineada; cortaban el hilo narrativo cuando les parecía bien para seguir su fantasía (interpretación propia). 
uno su propia autonomía; son dos registros distintos que el autor utiliza. Esta es una de las posibilidades. Roa Bastos escoge otra. El había comenzado con los «cuentos míticos» de El trueno entre las hojas. EI cuento que da el nombre a este ramillete de relatos cuenta de un barquero, Solano Rojas, que, luego de una huelga, volvió de la cárcel y que ya desde mucho tiempo atrás estaba muerto, pero cuyo acordeón todavía se escucha quejoso en esa "eléctrica noche de diciembre»: "Era una melodía ubicua, deshilachada. Se interrumpía y volvía a empezar en un sitio distinto, a lo largo de la caja acústica del río» ${ }^{12}$. Esta podría ser una descripción del cuento latinoamericano: «melodía ubicua, deshilachada... a lo largo de la caja acústica del río»; de modo significativo ella podría ser aplicable también a Hijo de hombre, una novela en la que la estructura del cuento y la de la novela se han unido en un todo pleno de tensiones, en una novela en cuyas nueve historias el cuento no regala nada a la novela, orgulloso como Macario, que escupe en el fuego y no narra nada más al acercarse una mujer.

La historia de Gaspar, la del médico ruso, la de Kiritó, que escondido en un árbol hueco da un chasco a las tropas del gobierno; la de Kiritó, quien, con los muñones atados al volante, conduce al frente el camión cisterna; la de Casiano y Natí, todos ellos son cuentos dentro de la novela, cuentos que contradicen, quiebran y fructifican a la novela.

Se ha señalado con razón que el modo de composición discontinuo que caracteriza las nuevas novelas latinoamericanas se halla en relación con el ejemplo de autores tales como Faulkner, Dos Passos, etc. No quiero negarlo; yo mismo lo he dicho. Pero, de todos modos, me parece que hay mucho que hablar en favor de que esos ejemplos han actuado tan poderosamente en América Latina porque ellos favorecieron su temperamento literario y su vocación narrativa tal como ellos se expresan en eI cuento. Gracias a los nombrados modelos externos y a la introducción del arte del cuento, la novela latinoamericana pudo convertirse en expresión de la propia relación con la realidad, lo que en la novela tradicional continua no era el caso. Una novela como La casa verde es por ello profundamente latinoamericana; es una novela que, con sus historias entrecruzadas, hace continuamente violencia a la novela; es una novela en la que el cuento lucha con la novela. Pedro Páramo es quizá el ejem: plo más hermoso y más patético de este antagonismo de los géneros dentro de la novela latinoamericana, de la función que puede cumplir el cuento en la nueva novela. Juan Rulfo había comenzado con los cuentos

${ }_{12}$ Augusto Roa Bastos, El trueno entre las hojas (Buenos Aires, 1976, 4. ${ }^{2}$ ed.), p. 225 . 
de El llano en llamas. Pedro Páramo, en cambio, es claramente una novela, es decir, un relato extenso, en el que se plantea la cuestión de la felicidad posible para el hombre en su mundo (el cuento, por su parte, como ya sabemos, presenta sólo una muestra incitante). ¿Pero qué no hace Juan Rulfo para afirmar el narrar artístico, la muestra y el cuento en la novela misma! Relata en varios estados temporales, apenas si deja al lector una posibilidad de ponerse cómodo, introduce a varios narradores, que a veces sólo son voces, que hablan desde cualquier lugar, a veces desde la tumba. La novela se convierte así en una serie de muestras que amenazan romperla en pedazos; tal como el héroe que le da nombre a la novela, se derrumba al final «como si fuera un montón de piedras». El resultado es una novela latinoamericana terriblemente joven, fruto de la violencia que aquí hace el cuento a la novela, para por fin sostenerse como Pedro Páramo ante el misterio de Susana. 
